\title{
LA TUTELA DE LOS MENORES EN EXTREMADURA DURANTE LA EDAD MODERNA *
}

\author{
$\mathrm{M}^{\mathrm{a}}$ Gema CAVA LÓPEZ
}

Universidad de Extremadura

\begin{abstract}
Resumen
La tutela representa en las sociedades tradicionales una actividad de destacado relieve debido a las implicaciones personales y patrimoniales que, para el menor y la familia, se derivan de su ejercicio. A la luz de tal consideración ha de entenderse la importancia de la persona designada para esta responsabilidad y la creciente preocupación de los progenitores por disponer acerca de esta materia. Las conclusiones obtenidas del análisis de las fuentes empleadas en este trabajo -testamentos y escrituras de discernimiento de tutelas- permiten confirmar ambos extremos al tiempo que descubren otras significativas evoluciones. Así, la progresiva inquietud de los testadores por nombrar a los tutores de sus menores y la mayoritaria elección efectuada sobre los miembros del núcleo conyugal, evidencian tanto la aparición de una nueva sensibilidad hacia las circunstancias de los menores huérfanos y la necesidad de dotarlos de instrumentos de protección más fiables, como las transformaciones operadas en el seno de la familia, a la que se reconoce como medio óptimo para el desarrollo emocional y educativo de los menores. De tal modo, los viejos intereses de preservación del capital familiar y de cuidado personal de los pupilos se suman a las inquietudes surgidas a fines del Antiguo Régimen para propiciar, en último término, un clima de mayor bienestar y atención afectiva a los menores por medio de la persona señalada para atender a ambas funciones.
\end{abstract}

Palabras clave: Tutela. Huérfanos. Extremadura. Edad Moderna.

\section{Abstract}

Guardianship in traditional societies is a really interesting activity due to the personal and economic implications that, for both the minors and their family, derive from its

* Este trabajo se inscribe dentro del proyecto de investigación para la elaboración de la Tesis Doctoral, dedicada a la Infancia en la Extremadura del Antiguo Régimen, que financia la Consejería de Educación y Juventud de la Junta de Extremadura por medio de una de sus becas de Formación de Personal Investigador. 
management. Bearing this in mind, one has to understand the importance of the person appointed for this responsibility and the growing concern of parents for deciding on this topic. The conclusions drawn from the sources used in this paper-wills and deeds of appointment of guardianships- have allowed us to corroborate both ideas and, at the same time, have discovered other significant evolutions. Thus, the gradual anxiety of parents for appointing the guardians of their minors and the majority choice made about the members of the nuclear family, show the appearance of a new sensitivity to the circumstances of minors orphans and the need to issue more reliable bills of protection for them, as well as the transformations occurred in the bosom of one's family, which is considered a very good atmosphere for the emotional and educative development during childhood. In this way, the old interests of preservation of the family capital and of personal care of wards join the anxiety arisen at the end of the Ancient Régime to provide, as a last resort, an environment of greater well-being and affective attention to the children by means of the person chosen to fulfill both functions.

Keywords: Guardianship. Orphans. Extremadura. Early Modern Period.

\section{CONSIDERACIONES PREVIAS A PROPÓSITO DE LA TUTELA}

En la pretensión de garantizar a los menores huérfanos las condiciones de vida durante la etapa infantil y prevenirlos de los posibles abusos de los adultos, considerando la falta de experiencia y juicio que se supone en ellos por razón de la edad, el Derecho castellano moderno mantiene vigentes las figuras, de larga tradición jurídica, de la tutela y la curaduría'; establecidas ambas sobre semejantes principios y objetivos, pero con atribuciones distintas que ayudan a una diferenciación neta de su significado y competencias. Esto es, si el tutor se define como el defensor y guardador del huérfano menor de catorce años, ocupado preferentemente en el cuidado y protección de la persona de aquél y en la defensa, en segundo término, de sus intereses económicos, por lo que importa al curador éste ejerce sus funciones en favor de los asuntos patrimoniales de los menores comprendidos entre catorce y veinticinco años, representando las atenciones personales a los mismos una responsabilidad accesoria dentro del conjunto de las asignadas ${ }^{2}$. De tal manera, la tutela constituye para la infancia carente de la protección de uno o ambos progenitores la garantía jurídica establecida por el Derecho a fin de proporcionar la asistencia indispensable en las labores de crianza, educación y salvaguarda de su capital, procurando de manera legal la aceptación de responsabilidades de otro modo abandonadas a la iniciativa de las solidaridades familiares y vecinales ${ }^{3}$.

A tenor de la multiplicidad y relevancia de las funciones que le son dadas, el tutor se convierte en sustituto efectivo de los progenitores, por cuanto sus atribuciones tra-

1. A propósito de los antecedentes en el Derecho histórico de ambas figuras, véase el trabajo de A. Merchán Álvarez, La tutela de los menores en Castilla hasta fines del siglo XV, Sevilla, 1976.

2. J. Febrero, Febrero Novísimo o Librería de Jueces, abogados y escribanos. Libro I. Edición de Don Eugenio de Tapia, Valencia, 1828, pp. 141-142.

3. Dubert García, Historia de la familia en Galicia durante la época moderna. 1550-1830, La Coruña, 1992, pp. 242-243. 
tan de dar plena cobertura a las necesidades habituales derivadas de la atención a los menores, y en elemento fundamental de control de las haciendas familiares que les son transmitidas por vía de herencia. Ello es así por cuanto debe proporcionar alimentación al pupilo con los recursos facilitados por el patrimonio personal de éste, educación, alojamiento -según lo dispuesto por el progenitor fallecido o la autoridad judicial-y estado a las menores; al tiempo que, en atención a las responsabilidades económicas, ha de atender al cuidado y administración de la hacienda, venta de frutos e inversiones al objeto de lograr no únicamente el incremento sino también la revalorización de las propiedades confiadas ${ }^{4}$. Compromisos, todos ellos, que aparecen explícitamente manifestados y asumidos en el proceso de discernimiento del cargo, conforme manifiestan las escrituras al respecto:

«(...) Domingo Sánchez (...), dixo que acceptaba y acceptó el cargo de tutor y curador de la persona y bienes de la dicha María Martin, pupila. Y bajo de juramento (...), prometió y se obligó con su persona y bienes muebles y raízes, pressentes y futuros, de ussar bien y fielmente, como debe y es obligado, el oficio y cargo de tutor y curador de la susodicha y sus bienes. Y que como tal, alimentará y regirá la persona de ella. Y también regirá y administrará, cobrará, arrendará y beneficiará todos los bienes, assí muebles como raizes, derechos, deudas y otros efectos que tiene y tuviere, assí en esta villa como fuera de ella, y pagará las deudas que estuviere debiendo con lo que procediere de dichos bienes. Y tomará legitimación de las pagas, hará inventario jurídico en tiempo y en forma, tendrá libro de qüentas y razón con debe y ha de haver; defenderá sus pleitos y caussas demandando y defendiendo en todas instancias, tomando para su mejor expedición consejo de abogado y de otras personas de ciencia y conciencia quando el suyo no bastare. Dará qüenta con pago, cierta y verdadera, con papeles y recados bastantes, y pagará el alcanze que se le hiziere; y entregará los papeles y scripturas y demás bienes que pararen en su poder a quien y como le fuere mandado debaxo de pena de execución, costas y apremio. Y en fin, hará todo aquello que como buen tutor y curador de persona y bienes debe y está obligado a hazer por derecho por su menor. Y si, por omissión, daño o pérdida le viniere lo pagará en la misma forma (...) »s.

En virtud de las importantes implicaciones personales y económicas que son susceptibles de derivarse de su actuación, vista la amplia relación de competencias contraídas, la normativa legal entiende conveniente la escrupulosa definición del estatuto del tutor, tanto por lo que respecta a la determinación de sus cualidades como a la precisión de las obligaciones y derechos reconocidos, con la finalidad de garantizar el riguroso ejercicio de sus responsabilidades y preservar, en último término, los intereses del menor. A tal efecto, el Derecho castellano excluye a mujeres, menores, discapacitados físicos o psíquicos, deudores y acreedores del pupilo además de los miembros de determinados grupos sociales o de actividad -religiosos, administradores de rentas reales, caballeros y soldados- de la posibilidad de desempeñar las funciones

4. J. Febrero, op. cit., p. 161.

5. A(rchivo) H(istórico) P(rovincial) de C(áceres). Sección Protocolos. Robledillo de Gata. Año 1705. Caja 1.563; legajo 12.

6. J. Febrero, op. cit., p. 143. 
tutelares ${ }^{\circ}$, al entender en ellos sujetos carentes de las facultades requeridas para la eficaz gestión de los asuntos encomendados cuando no una presumible mala predisposición hacia el menor, caso de los deudores del mismo. Las exigencias legales no quedan, sin embargo, restringidas a la fijación de los requisitos de idoneidad mencionados, sino que en cualquier caso la actividad tutelar es sometida al cumplimiento estricto de aquellos procedimientos mediante los cuales se pretende, en palabras de Merchán Álvarez, la delimitación «[d]el ámbito de responsabilidad patrimonial del tutor en cuanto que con ellos se determinan los bienes que han de ser administrados y cómo ha sido realizada su gestión o administración ${ }^{7}$. En este sentido, el juramento del cargo ante juez o escribano con presentación de fianzas -a excepción de los designados por manda testamentaria-, la elaboración del inventario de bienes tras el discernimiento de la tutela y la rendición de cuentas definen los límites de la capacidad de actuación consentida al tutor y testimonian la voluntad de fiscalización de su actividad por parte de las autoridades judiciales ${ }^{8}$. Pese al esfuerzo de control que traducen las medidas apuntadas, los abusos y demoras en el ejercicio de ciertos deberes, tales como la declaración del balance contable de la tutela, no debieron ser infrecuentes; así lo demuestran los ocasionales requerimientos presentados ante la justicia para exigir su cumplimiento o las cautelas manifestadas por los progenitores en sus últimas voluntades, en las que se apela de manera explícita al respeto riguroso a las formalidades dictadas por la ley:

«A la qual dicha mi hija, por ser menor, le nonbro por curador, desde luego que yo sea muerto, a mi ermano Francisco García a el qual pido a la justicia le nonbre y aya por nonbrado desde luego que yo sea muerto \según yo le nonbro/. A el qual se le entrieguen todos los bienes que tocaren a dicha mi hija por ynbentario de qüienta y racón (sic), para que en todo tienpo conste lo que es de la dicha mi hija (...)»".

Siendo cierto, a juzgar por lo que sugieren las medidas cautelares apuntadas, que en determinadas ocasiones la tutela de un menor debió constituir una circunstancia propicia para la mejora del patrimonio del tutor por medio de la expoliación ilícita de los bienes de su pupilo ${ }^{10}$, en términos generales el nombramiento para tal función, ha-

7. A. Merchán Álvarez, op. cit. p. 141.

8. Idéntico celo está presente en los fundamentos de las normas reguladoras de la tutela en los cuerpos legislativos medievales castellanos, italianos y del Derecho catalán. Al respecto puede consultarse el trabajo ya citado de A. Merchán Álvarez y los respectivos de N. Guglielmi, «La viuda tutora (Italia del centro y del norte. Siglos XIII-XV)», Anuario de Estudios medievales, 18, 1988, pp. 157-171 y C. Forns de Rivera, «El ejercicio de la tutela por las mujeres de los ciudadanos de Barcelona (siglos XIIIXIV)» en M. V. López Cordón y M. Carbonell Esteller (ed.), Historia de la mujer e historia del matrimonio, Murcia, 1997, pp. 53-63.

9. A.H.P.C. Sección Protocolos. Aliseda. Año 1681. Caja 3.555; legajo 13.

10. A propósito de ello, F. J. Lorenzo Pinar apunta en su trabajo las apelaciones efectuadas por las Cortes ante el Monarca al objeto de intensificar los medios de control y revisión de la gestión tutorial ante los numerosos casos de pérdida de haciendas en manos de tutores y curadores. F. J. Lorenzo Pinar, «La familia y la herencia en la Edad Moderna zamorana a través de los testamentos», Stvdia Historica. Historia Moderna, IX, 1991, p. 176. 
bida cuenta de las múltiples cargas que supone y del ejercicio de supervisión al que se encuentra sometido, representa para los adultos concernidos una responsabilidad gravosa que, en la medida de lo posible, se esfuerzan por eludir. Con independencia del medio social analizado, todas las investigaciones coinciden en señalar el escaso interés y aprecio que suscita la designación para el cargo, con excepción de aquellos supuestos en los que la cuantía de los bienes pudiera hacer atractiva su administración. No en vano la propia esfera jurídica es sensible a la valoración peyorativa que, desde el punto de vista de la percepción social, merece esta actividad, por lo que no duda en calificarla como "gravoso cargo" al que no obstante «todos pueden ser compelidos (...) porque es oficio público y necesario» ${ }^{\prime \prime}$. En consecuencia, no resultan extrañas las apelaciones presentadas ante la justicia por los mismos individuos designados con la finalidad de ser exonerados del nombramiento bajo pretextos diversos. Entre los empleados figuran la incompatibilidad con otras ocupaciones, la ausencia de obligación dado el grado de distanciamiento del parentesco con relación al menor, la enfermedad, la incapacidad física del tutor inicialmente señalado u otros del tipo de los relacionados en la amplia argumentación presentada por Francisco Martín, en virtud de la cual quedará finalmente dispensado en favor del pariente a quien legítimamente debía corresponder el deber:

«Francisco Martín, vecino d'este villa, digo que vuestra merced fue serbido de nombrarme por tutor y curador de Francisco, hijo de Pedro Brabo Peña, ya difunto, y la justicia mediante vuestra merced se a de serbir de darme por libre de dicha tutela por tres causas. La primera es por tener como tiene dos tíos. El uno es Alonso Brabo Peña, ermano del dicho Pedro Brabo, que es a quien toca por saber leer y escribir, y el otro es Juan Doninguez Maia, hijo de una ermana del dicho Pedro Brabo, que tanbién sabe leer y escribir y ser como son hombres desocupados y asistir todo el año en esta villa (...). Lo otro porque yo no sé leer ni escribir y estar toda la más parte del año ocupado en mi labor y grangerias. Lo otro por ser un hombre de más de cinquenta y tres años y allarme muy ynpedido con dichas ocupaciones» ${ }^{12}$.

Conscientes de tales dificultades y del esfuerzo que representa la custodia de las personas y bienes de los pupilos, tanto la normativa vigente como los progenitores vinculados a menores se esfuerzan en compensar y procurar el mayor atractivo del cargo por medio de los incentivos contemplados por la ley. Los tutores se ven así favorecidos por el derecho que les asiste a ser perceptores, en concepto de retribución, de la décima parte de los rendimientos obtenidos por los bienes naturales, industriales y civiles del menor que «se les debe no como verdaderos usufructuarios y por título lucrativo, sino como acreedores por el oneroso que es su trabajo» ${ }^{13}$. Además de ello, por lo que concierne a la capacidad dispositiva de los padres, éstos explotan, en favor de lograr las mayores facilidades para la aceptación del cargo, la facultad que les otorga la legislación para ratificar a los nombrados por manda testamentaria exentos

11. J. Febrero, op. cit., p. 166.

12. A.H.P.C. Sección Protocolos. Brozas. Año 1681. Caja 2.642-3; legajo 15.

13. J. Febrero, op. cit., p. 173. 
de la presentación de fianzas y eludir, en tanto sea posible, la participación de las autoridades judiciales y el encarecimiento de los costes protocolarios que ello ocasiona ${ }^{14}$, tal y como hiciera Pedro Hernández Calderón al ordenar:

«Yten, mando y es mi voluntad que para que cuide de mi hijo y sea su curador de mi hijo Francisco y de sus bienes, (...) dejo y nonbro para este efeto a mi sobrino Juan Garido (sic) (...); y así, le nonbro y relievo (sic) de toda fianza porque se cuidará de todos sus bienes del dicho mi hijo y que dará qüenta de ellos como es obligado.

Yten, es mi voluntad que no entre justicia en mis bienes, si tengo derecho para ello. $Y$ que si a de entrar la justicia, quiero y es mi voluntad entre mi ermano Alonso Martín, que oy se halla siendo alcalde, el qual quiero que inbentaríe mis bienes y los entriegue (sic) al dicho curador que llevo aquí nonbrado (...) ${ }^{15}$.

El celo que traslucen disposiciones como las anteriores, empeñadas en lograr la traducción fiel y efectiva de las voluntades de los progenitores y asegurar su máximo nivel de intervención en esta materia, ha de ser interpretado, más allá del objetivo único de lograr la protección más idónea de la persona del menor, en relación al significado que adquiere la tutela en orden a los intereses patrimoniales que incumben a todo el grupo de consanguíneos, por cuanto tutorías y curadurías se convierten en instrumentos esenciales de dominio y gobierno de las haciendas familiares ${ }^{16}$. Bajo tal consideración adquiere aún mayor relieve no sólo la identidad de la persona de confianza en la cual recaerá la gestión de los bienes, sino también el grado de intervención e interés de los allegados en esta materia, en aquellas ocasiones en las que se requiera su colaboración en las asambleas de parientes, constituidas para resolver a propósito de la designación de los tutores. Si bien la composición de estas juntas de parientes es ampliamente conocida para el caso francés ${ }^{17}$, habiéndose puesto de manifiesto por medio de diversas investigaciones las estrategias seguidas en su formación a tenor de la línea de patrimonio que pretende salvaguardarse, las fuentes propias no han permitido ninguna clarificación en este sentido en las localidades donde se documenta la práctica de su convocatoria para decidir acerca de los asuntos que afectan a los huérfanos. Por lo cual, no ha sido posible la ponderación del nivel de inquietud y preocupación suscita-

14. D. González Cruz, Familia y educación en la Huelva del siglo XVIII, Huelva, 1996, p. 250.

15. A.H.P.C. Sección Protocolos. Aliseda. Año 1695. Caja 3.557; legajo 27.

16. M. García Fernández, Herencia y patrimonio familiar en la Castilla del Antiguo Régimen (1650. 1834), Valladolid, 1994, p. 297.

17. En relación a las competencias, funcionamiento y composición de las asambleas de parientes francesas pueden consultarse los trabajos de M. Baulant, «La famille en miettes: sur un aspect de la démographie du XVIle siècle», Annales E.S.C., 27, 1972, pp. 959-968. S. Pierrer, «Rôles des réseaux de parenté dans l'education des mineurs orphelins selon les comptes de tutelle parisiens (XVIle-XVIIIe siècles), Annales D.H., 1995, pp. 125-135. J. P. Bardet, «Les procès-verbaux de tutelle: une source pour la démographie historique» en VV. AA., Mesurer et comprendre. Mélanges offerts à Jacques Dupâquier, Textes réunis et publiés par J. P. Bardet, F. Lebrun, R. Le Mée, París, 1993, pp. 1-2 I. M. Garden, «Les relations familiales dans la France du XVIIe siècle: une source, les conseils de tutelle», en VV. AA., Les actes notariés. Source de l'Histoire sociale, XVIe-XIXe siècles, Actes du Colloque de Strasbourg (mars, 1978), réunis par B. Vogler, Estrasburgo, 1979, pp. 173-186. 
dos entre los consanguíneos por participar en aquellas deliberaciones que atañen al control del capital familiar. No obstante, las referencias dispersas, localizadas a lo largo de los protocolos, ofrecen noticias significativas sobre los particulares esfuerzos acometidos por los familiares más cercanos al pupilo por mantener una influencia directa sobre los bienes heredados, lejos de cualquier intromisión externa. En este contexto aparecen las peticiones de aquellas madres que, pese a haber contraído segundas nupcias, reclaman para sí la custodia de sus hijos y bienes o la de hermanos que pretenden idénticos fines en detrimento, en cualquiera de los casos, de los tutores establecidos:

«Sépase por esta pública escritura de tutela cómo yo Thomás Piernas, (...) digo que por fallecimiento de mi madre Antonia Eleuteria Gómez quedaron diferentes bienes muebles y raices para haverse de partir entre mí y mi ermano Benito Piernas. Cuia diligencia habiéndose practicado, se nos nombró por su testamento (...) a Juan de la Cruz Godoy y a Manuel Moreno Santano, de esta vezindad, por nuestros tutores y curadores (...), mediante a la menor edad en que nos quedó; y como haya yo pasado a recivir estado de matrimonio, por el que quedo capaz para por mí administrar los que me correspondan, he pedido judicialmente que aquéllos se excluian de la dicha administración y se me tenga por apto para ejercerla no sólo de los míos, sino también de los que correspondan a dicho mi ermano, lo que me fue otorgado como solicité (...). Lo que poniendo en efecto, otorgo que me obligo y constituio a ser su tutor y curador (...). Y también me obligo a continuar con él procurando su conservación en los estudios en que se halla para colocarse en el estado sacerdotal (...). Y de todo llebaré la exacta cuenta que es devida hasta tanto que se halle capaz para él por sí poder ser el administrador; de cuio cargo en aquel entonces me desistiré, como de el de la administrazión de los bienes y rentas eclesiásticas, que goza y obtiene con otros que hubo por donación de nuestro tio don Benito García Gomes, los cuales todos se hallan a mi cargo y cuidado (...) ${ }^{18}$.

La sola observación de los resultados, por lo que concierne a la orientación de las designaciones, no deja lugar a dudas sobre la sensible cuestión que supone la elección de los tutores y, en razón de ello, el destacado papel atribuido a los consanguíneos como principal grupo comprometido no únicamente en el cuidado personal, en virtud de los deberes y vínculos morales y jurídicos que crea el parentesco ${ }^{19}$, sino también en la gestión económica de los menores. La conciencia de la especial atención y celo que merecen las decisiones adoptadas en esta materia se evidencia sin dificultad en el creciente y expresivo volumen que registran las disposiciones de tutores nombrados por orden testamentaria de los progenitores, tanto como en los reiterados testimonios justificativos y declaraciones de intenciones que suelen acompañarlas. En esta línea, las manifestaciones de satisfacción y confianza en el buen trato hacia el menor y en la gestión leal y eficaz del patrimonio que se esperan obtener del individuo señalado, son referencia común en las cláusulas testamentarias en las que se instituyen tutores,

18. A.H.P.C. Sección Protocolos. Aliseda. Año 1798. Caja 3.847; legajo 15.

19. Respecto a la naturaleza e implicaciones de las relaciones de parentesco en las sociedades tradicionales puede consultarse el capítulo correspondiente en la obra de J. L. Flandrin, Orígenes de la familia moderna, Barcelona, 1979. Edición original francesa, 1976, pp. 19-67. 
junto a ocasionales declaraciones de rechazo a la injerencia de extraños al grupo familiar e incluso de las propias autoridades judiciales:

«Yten, nombro desde luego por madretutriz, tutora y curadora de los dichos Francisco, Juan, Joseph y Nicolás, mis hijos y suyos, para que la sussodicha, la dicha Maria Gómez. Marinero, mi muger, a su disposición declare y entere de todos mis vienes y hazienda (...) a los dichos mis hijos. Y por sí haga o pueda hazer inventario de todo lo que fuere de dichos mis hijos sin que la justicia pueda entrometerse en cossa alguna, porque yo lo dexo todo a la dispossición de dicha mi muger por la conffiança que de ella tengo y que administtrará y cuidará de dichos mis hijos y de sus alimentos por los días de su vida y les dará todo lo que fuere suyo, relevándola, como desde luego la relevo, de toda satisfación y fiaduría de dicha tutela y curadoría; encargando a dichos mis hijos en todo que sean muy obedientes y nunca salgan de su horden y mandado, que assi es mi voluntad (...) ${ }^{20}$.

Finalmente, en un planteamiento global a propósito de los asuntos concernidos y las implicaciones personales, sociales y familiares que convergen o se derivan de la práctica tutelar, resulta de obligada referencia la consideración de los efectos que sobre las condiciones de vida del menor conlleva la diferente elección de los individuos que habrán de asumir las responsabilidades tutelares. La designación constituye un hecho en extremo delicado por cuanto en último término es determinante de las circunstancias en las que habrá de desenvolverse la etapa infantil del menor desde el punto de vista material y afectivo, al decidir desde el marco de residencia y educación al grado de vinculación mantenido con el progenitor superviviente o el grupo familiar de pertenencia.

La ratificación por vía testamentaria de la tutela en la figura de la madre, o el simple reconocimiento del derecho legítimo que le corresponde al ejercicio de tal función, representa el mantenimiento del niño en el propio ámbito doméstico dentro de un clima de relativa continuidad con respecto a la situación previa a la desaparición del progenitor. De tal manera, la mayoritaria elección efectuada por los varones en la persona de la madre y esposa, junto a la documentación de otra práctica encaminada a la conservación de la unidad familiar por medio de la cesión del usufructo de la hacienda en favor de aquélla bajo el compromiso de asumir la crianza y educación de los menores, aun cuando no sea designada de forma explícita como tutora y curadora de los mismos ${ }^{21}$, advierte de la clara intención del padre de procurar el mantenimien-

20. A.H.P.C. Sección Protocolos. Robledillo de Gata. Año 1696. Caja 3.286; legajo 26.

21. Las disposiciones al respecto se encuentran presentes en el $17,2 \%$ de los testamentos escriturados en la centura del Quinientos cuyo titular manifiesta tener hijos en la edad pupilar, reduciéndose la proporción de semejantes declaraciones en fechas posteriores, en las que tan sólo han sido localizadas en el $7,8 \%$ y el $1,8 \%$ de las escrituras relativas a los siglos XVII y XVIII en tanto es apreciable un expresivo crecimiento del número de designaciones explícitas del cargo.

22. En Cataluña, Valencia y Baleares se documenta la práctica de este usufructo viudal, establecido mediante capitulaciones matrimoniales o claúsula testamentaria, en las mismas condiciones de cesión de la administración y rendimientos de los bienes del progenitor difunto a favor del cónyuge superviviente, bajo el compromiso de mantener el estado de viudedad y su dedicación a las atenciones de los me- 
to de los vínculos y la organización familiar en favor de la custodia y la atención sentimental de los menores, bajo la responsabilidad de la madre en tanto mantenga el estado de viudedad ${ }^{22}$ :

«Yten, es mi boluntad de mandar y mando, por los días de su vida hasta que se case, a mi mujer, Maria Hernández, todos mis bienes muebles y rayzes que me toquen y pertenezcan para que durante los días de su vida los goze y desfrute (sic) y pague los que yo deviere de deudas y zensos. $Y$ si se casare, luego que se case, buelvan a mis herederos y los partan ygualmente entre ellos y espire dicha manda el día que se casare dicha María Hernández. Y con calidad que críe y alimente a mis hijos y los vaya poniendo en estado, dándoles de dichos mis bienes conforme a su calidad de cada uno. Y si alguno de mis hixos o hixas pidieren soldadas, es mi boluntad que a el que las pidiere desde luego, para quando las pida, le desheredo del tercio i quinto de mis bienes y los partan entre los que no las pidieren ${ }^{23}$.

Idénticos instrumentos disuasorios de un nuevo matrimonio de la esposa, susceptible de ocasionar el abandono del cuidado de las personas y bienes de los pupilos en manos de tutores y de contribuir a la merma del patrimonio de los mismos, al obligar a la restitución de la dote aportada por la mujer al matrimonio, se hallan testimoniados ya en la Florencia bajomedieval de los siglos XIV y XV; semejante constatación resulta del mayor interés por cuanto pone de relieve la significativa persistencia, dentro de una secuencia temporal amplia, de similares riesgos y cautelas, cualquiera que sea el espacio social y geográfico de estudio. En este caso, como ha sido también advertido en los territorios de la corona de Aragón o en la Castilla moderna, rentas, usufructo de bienes, ventajas suplementarias, potestad para gestionar los bienes del esposo difunto y disposiciones dirigidas a los herederos al objeto de procurar el respeto y la consideración de éstos hacia la madre viuda, constituyen los mecanismos incentivadores de los que se sirve el testador para asegurar la permanencia de la esposa al lado de los huérfanos menores de edad ${ }^{24}$. En último extremo, las segundas nupcias de la madre no suponen necesariamente en todos los casos la ruptura de los lazos y la salida de los menores de la casa materna. Declaraciones de distinta naturaleza aluden a la permanencia de los menores en el hogar rehecho por la madre, al cuidado de ésta y del padrastro, si bien en el marco de una nueva relación mediatizada por el interés económico que representa el pago de los gastos ocasionados por la crianza de los menores, a partir de sus propios recursos, ahora gestionados por el tutor legítimo que sucedió a la madre. En parecidos términos debió llevarse a cabo la crianza de María Durana, en compañía de su madre y padrastro, a tenor de lo expresado por éste en su testamento:

nores huérfanos. E. Gacto, «El grupo familiar de la Edad Moderna en los territorios del Mediterráneo hispánico: una visión jurídica» en J. Casey et al., La familia en la España mediterránea (siglos XVXIX), Barcelona, 1987, p. 48.

23. A.H.P.C. Sección Protocolos. Hoyos. Año 1655. Caja 595; legajo 68.

24. C. Klapisch-Zuber, «La "mère cruelle". Maternité, veuvage et dot dans la Florence des XIVe-XVe siècles», Annales, E.S.C., 5, 1983, pp. 1.097-1.105. 
«Yten, declaro que durante el matrimonio que tuve con Catalina Dominguez, mi mujer difunta, mujer que avía sido de Juan Durán, andava en arriendo la persona y vienes de María Durana, yja de los dichos y mujer que al presente es de Mateo Benito Longo, la qual por ser de poca edad le señalaron alimentos y nosotros la teníamos en casa. Y para descargo de mi conciençia digo que, por mano de Domingo Picado de la Fuente cobré dos años de alimentos de que le dí carta de pago, y no sé la cantidad que era; y por las posturas constará lo que le corresponde de alimentos a dichos dos años, porque aunque eran tres yo no cobré más de dos (...)» ${ }^{25}$.

Junto a circunstancias como la que acaba de referirse, la documentación aporta ejemplos particulares a propósito de las diversas vías explotadas a fin de procurar el mantenimiento y relación del menor con su familia de origen, algunas de las cuales se traducen en situaciones a priori anómalas desde el punto de vista de la normativa legal, aunque aceptadas en la práctica cotidiana de las comunidades. En este sentido, la realidad refleja la aceptación de buen grado, por parte de las autoridades y del colectivo social, de la tutoría reclamada por la madre nuevamente casada o adjudicada al padrastro del menor. Ello, pese a la unanimidad de criterios y posicionamiento estricto de los cuerpos jurídicos frente a la tutela desempeñada por la madre, concebida en todos los casos como «un tipo muy especial de tutela que puede ser considerada (...) como una excepción a la incapacidad de la mujer para ser tutora por razón de sexo» ${ }^{26}$, y a las extremadas precauciones adoptadas para este ejercicio, las cuales determinan el relevo inmediato en el cargo tras las segundas nupcias de la madre ante el temor de enajenación de los bienes de los menores o riesgo para la vida de los mismos, por efecto de la influencia del nuevo esposo ${ }^{27}$. La última solución de las apuntadas, si bien comporta la dejación de las responsabilidades de gestión de las haciendas y la atención directa de la persona del pupilo en manos de un extraño al grupo de consanguíneos, ofrece en contrapartida la posibilidad de permanencia en un núcleo familiar reconstruido bajo la supervisión y cuidados que pueda prestar la madre. La confianza mostrada hacia los padrastros parece reproducirse, de igual modo, en la figura de la madrastra, en favor de la cual han podido ser localizados testimonios de conformidad efectuados por testadores nuevamente desposados y con cargas familiares de anteriores matrimonios. Dichas disposiciones revelan la total aprobación y reconocimiento de la labor educativa y administrativa que se espera de ella, en provecho de los intereses de los huérfanos, al ser designada para ejercer idénticas responsabilidades y disfrutar de los mismos beneficios que ya fueran señalados para las propias esposas y madres de los pupilos. Ejemplo de los extremos referidos es el testamento de Alonso Domínguez, en el que dispone en atención a su segunda esposa e hijo:

«Yten, mando que la dicha Lorença Sánchez goze por los días de su vida, a lo menos mientras Alonso mi hijo no se casare o fallesciere, del gozo d'estas casas y de toda mi hazienda, con que tenga y mantenga, vista y calçe al dicho Alonso, mi hijo, y labre y pe-

25. A.H.P.C. Sección Protocolos. Hoyos. Año 1682. Caja 30; legajo 52.

26. A. Merchán Álvarez, op. cit., p. 148.

27. J. Febrero, op. cit., pp. 144-145. 
che mi hazienda y la qu'el dicho mi hijo tiene de su madre. Y si acaso el dicho mi hijo no quisiere estar con la dicha mi muger antes que se case o su curador se le quitare, en tal caso como éste o en caso que pida soldada a la dicha mi muger, aya y lleve el quarto de mis bienes $(\ldots)$.

(...) La dicha mi muger se esté e no la saquen de la dicha casa, porque yo mando esté en ella y la abite y more por sus días por el amor que le tengo y en virtud de la escriptura de dote y arras que tengo fecha en su fabor que apruevo (...) de presente, e por la confiança que d'ella tengo de que tratará y regalará al dicho mi hijo el tienpo que con ella estuviere (...) $)^{2 *}$.

Por contraste con las circunstancias apuntadas, la puesta de los menores bajo la autoridad y cuidados del tutor, no siendo éste uno de los mismos progenitores, es generadora de una multiplicidad de situaciones, por cuanto no existe una determinación previa del destino y condiciones materiales y educativas en las que habrá de desarrollarse la infancia del huérfano tutelado. Las fuentes testimonian un diverso abanico de posibilidades entre las que figura la crianza bajo vigilancia directa del tutor, aun cuando el alojamiento en su propia casa no constituya una obligación inherente al cargo. Las escrituras derivadas de la presentación de las cuentas al término del ejercicio de la tutoría reflejan la presencia del menor en el domicilio de aquél, ya sea de forma transitoria, ante la ausencia de terceras personas interesadas en la tenencia del menor por la retribución convenida entre ambas partes, o con un carácter más permanente; en cualquiera de ambos casos, siempre supeditada a la remuneración de los gastos de manutención, cuyo presupuesto es determinado por la autoridad competente o la junta de parientes que resuelve en tales cuestiones:

«Más da en descargo quatrozientos reales que por un despacho que presentó firmado de Don Salvador Álbarez, correxidor que fue de la ziudad de Coria, por donde consttó averle dado lizencia al dicho curador para que de los vienes de la dicha menor sacase en cada un año para sus alimentos dicha cantidad. $Y$ dicho curador la tubo alimentanda (sic) un año y el demás tienpo que yrá referido. Y se le deven pasar por mandarlo ansí dicho señor Don Salvador Álbarez de Azevedo por su despacho (...) $\gg^{20}$.

Un segunda alternativa contemplada por la política tutelar viene dada por la puesta del menor al cuidado de terceras personas, por medio de fórmulas contractuales de marcado carácter mercantil como las documentadas en las localidades de Acebo, Hoyos y Robledillo de Gata. En los núcleos mencionados se comprueba la práctica de la subasta pública del menor al objeto de ser cedido en régimen de soldada o al mejor postor interesado en ofrecer alojamiento y manutención; en este último caso, a cambio de los beneficios obtenidos de la explotación de la hacienda del pupilo, de la que se hace entrega al adjudicatario, o de la remuneración en metálico concertada. Este uso, eficaz desde el punto de vista de la gestión económica de la tutela, dado que responde hábilmente a las exigencias de crianza y gestión patrimonial del pupilo, signi-

28. A.H.P.C. Sección Protocolos. Robledillo de Gata. Año 1593. Caja 1.170; legajo 28.

29. A.H.P.C. Sección Prolocolos. Hoyos. Año 1686. Caja 405; legajo 64. 
fica sin embargo un procedimiento escasamente favorable a las atenciones personales del menor y a la creación de un marco estable y seguro de crecimiento durante la etapa de desarrollo infantil. En apoyo de esta consideración baste observar las referencias conocidas a propósito de la naturaleza de los beneficiarios de dichas subastas y de la periodicidad con la que se produciría la renovación de la adjudicación, y con ello el posible cambio de domicilio de acogida del menor. De acuerdo con los datos aludidos, en el $83,8 \%$ de los casos localizados entre 1581 y 1708 los interesados se corresponden con individuos no identificados explícitamente por mantener una vinculación familiar con el pupilo, estableciéndose los contratos entre éstos y los respectivos tutores por una duración media comprendida entre los catorce meses estipulados en el siglo XVI a los tres años concertados en las escrituras de la primera década del Setecientos, al término de los cuales se procedería bien a la revalidación de la cesión del menor bien a su nueva puesta a subasta pública ${ }^{30}$. A tenor de lo expuesto, no resulta difícil especular a propósito de las implicaciones a nivel subjetivo y afectivo que habrían de derivarse de medidas en las que únicamente parecen ser contemplados y primados los aspectos patrimoniales de los tutelados:

«(..) Andrés Rico (...), como curador de la persona y vienes de Alonso Rico, menor, por ante mí el escrivano dijo que los vienes de dicho menor se componen además de una casa qu'está arrendada, de un pedaço de viña a el Rebentón y de un güertillo a la Corredera; y cumpliendo con su obligación me pide aga un edito en que se diga que quien quisiere acer postura en el aprovechamiento de la persona y vienes de dicho menor, por uno o más años asta que él cumpla con su oficio de curador, se la recibirá. Y fecho, se fije en el poste de la plaça pública d'este lugar para que venga a noticia de sus vecinos y se ponga a continuación por fe y dilixencia para de no aver ponedor, administrar con qüenta y raçón, a gasto y recibo (...) $)^{3}$.

Existe, no obstante, una opción atenuada consistente en el establecimiento de acuerdos entre los parientes del menor, reunidos en asamblea, y los interesados en su cesión, por medio de los cuales logran ser cubiertos idénticos objetivos si bien a través de instrumentos en los que se hace intervenir la capacidad de elección y la consideración de los parientes. De tal modo, la atención a los requerimientos de alojamiento, manutención, vestido, conservación de la hacienda -cuyos frutos son entregados en concepto de retribución-, pago de pechos e incluso compensación económica por los servicios que pudiera prestar el pupilo, constituyen una vez más los términos contemplados en la relación contractual, ahora sometida al juicio de los allegados, con lo cual se logra un tratamiento más personalizado y deferente hacia el huérfano. Prueba de ello han de ser tanto las declaraciones de intenciones insertas en los protocolos que recogen esta práctica, en las que se alude a las conveniencias educativas y afectivas del menor como elementos de juicio en la toma de decisiones, como los significativos resultados que apuntan a los parientes como principales adjudicatarios, $59,1 \%$ de los

30. M. G. Cava López, «Economías infantiles: recursos materiales y gestión del patrimonio de los huérfanos extremeños durante la Edad Moderna», Obradoiro de Historia Moderna, 8, 1999, pp. 91-97.

31. A.H.P.C. Sección Protocolos. Hoyos. Año 1687. Caja 32; legajo 57. 
individuos presentes en los conciertos acordados entre 1556 y 1651 , en virtud de su mayor idoneidad:

«(...) Dixeron que ellos eran convenidos e conçertados y lo fueron con el dicho Martín Sánchez Viejo, tío del dicho menor, para que tenga e mantenga, vista e calçe como es razón e costunbre d'esta villa, al dicho Andrés Rodríguez, menor, por tienpo y espacio de tres años cunplidos (...); todo lo qual votaron e conçertaron con el dicho Martín Sánchez, tio del dicho menor, por pareçerles como les pareçe así conviene al bien del dicho menor por ser como es pequeño y niño y que con su tío estará mejor que con otra persona alguna y porque le comiençe a avezar a trabajar y le enseñe lo bueno y porque no ande en arrendamientos donde le traten mal y sea más pérdida del dicho menor. Para todo lo qual y para ayuda al sustento y regalo del dicho menor y para que con mejor gracia lo tenga y regale, votaron los dichos parientes y el tutor en darle y le dieron al dicho Martín Sánchez con el dicho menor, por tienpo y espacio de los dichos tres años, el gozo y aprovechamiento de la viña de Barrigas que tiene el dicho menor (...) y unas oliveras ${ }^{32}$.

\section{LA DESIGNACIÓN DE TUTORES}

En conformidad con la normativa legal, la elección del tutor se hace efectiva a través de tres procedimientos - distintos en cuanto a la prioridad que se concede a cada uno de ellos, la inmediatez con la que se determina al designado y el sujeto que decide la elección-, establecidos conjuntamente como un sistema de garantías sucesivas orientado a asegurar la presencia de dicha figura junto al menor. Más allá de la posibilidad de análisis de las variadas fórmulas creadas para dar cumplimiento a las obligaciones del Derecho y de los elementos implicados en dichas responsabilidades, el estudio de las distintas tipologías que presenta la tutela ${ }^{33}$ resulta de interés por cuanto permite el conocimiento de las diferentes orientaciones de aquélla y el carácter de las redes de solidaridad así surgidas. A tal objeto, los testamentos se convierten en una fuente útil mediante la cual valorar el grado de inquietud de los progenitores por servirse de los instrumentos dispuestos por la ley para procurar las mayores garantías asistenciales a sus menores, y por la que perfilar el sentido que sigue la búsqueda de apoyos y confianzas dentro del grupo familiar. Por su parte, el estudio de la segunda fuente que constituyen las escrituras derivadas del proceso de aprobación de las tutelas facilita el análisis de los instrumentos jurídicos y sociales creados a fin de solven-

32. A.H.P.C. Sección Protocolos. Robledillo de Gata. Año 1605. Caja 1.659; legajo 4.

33. Las distintas clases de tutelas pueden ser englobadas en dos grupos que distinguen los sistemas automáticos de designación de tutor -en los que se incluyen la tutela testamentaria y la legítima- y los sistemas no automáticos de designación de tutor -a los que se asocian la tutela dativa y la tutela subastada-. La tutela testamentaria es otorgada por testamento a favor de los hijos legítimos, póstumos, naturales o herederos extraños del testador; ésta es en cualquier caso preferente al resto de los tipos. La $t u$ tela legítima supone una fórmula supletoria de la anterior, otorgada a los parientes del pupilo, en ausencia de disposiciones testamentarias al respecto, según un orden de prelación establecido sobre criterios de parentesco. En último lugar, la tutela dativa es determinada por la autoridad judicial ante la falta de las anteriores, pudiendo intervenir también la decisión de los parientes en la designación del nombrado. A. Merchán Álvarez, op. cit., p. 75. J. Febrero, op. cit., pp. 146-151. 
tar la sensible cuestión de la atención personal y patrimonial de los menores, así como la indagación de los vínculos establecidos desde la interpretación no individual del testador sino del colectivo. En último término, la información suministrada por ambos testimonios se conjuga para dibujar un panorama contrastado de las distintas prácticas y circunstancias asociadas a los menores huérfanos, e insinuar las condiciones de vida determinadas por aquéllas, según se ha visto; por añadidura, a estas consideraciones propias, cabe aún sumar las expresadas por I. Dubert para el cual la impottancia del examen de la documentación relacionada con el discernimiento de tutelas «radica en las posibilidades que ofrece para comprender el papel de la infancia en un mundo de adultos (...), para analizar la importancia de la mujer, para acercarnos a los problemas que se derivan de su adjudicación, a la personalidad de los depositarios, etc. ${ }^{34}$.

Por lo que importa a la primera de las fuentes sugeridas, la observación de la proporción de testamentos de adultos con responsabilidades contraídas con menores en los que se declara el nombramiento de tutores ${ }^{35}$, permite avanzar la impresión de la evolución positiva que manifiesta tal interés a lo largo de los tres siglos de análisis, confirmando a priori los destacados progresos que experimenta el trato dispensado al niño en el propio ámbito familiar. Ciertamente, las escrituras testamentarias del área investigada muestran, en términos generales y de forma inequívoca, una tendencia creciente en el número de tutelas ordenadas en las últimas voluntades, tan sólo demorada en los momentos críticos de los inicios de las centurias del Seiscientos y Setecientos y posteriormente consolidada tras la segunda mitad del siglo XVIII. Así lo confirma el movimiento de los porcentajes, oscilantes desde el $31 \%$ ofrecido por los primeros cien años contemplados al 73,5\% estimado para el último siglo ${ }^{36}$, coherente con el paralelo incremento registrado en otras zonas de la Corona de Castilla, según apunta la práctica testamentaria de la Zamora moderna o la ciudad de Valladolid entre 1650 y 1834 en la que es apreciable a fines del XVIII un crecimiento, unísono en este sentido, en la capital y áreas rurales próximas a ella ${ }^{37}$. El paulatino cambio de actitud en el transcurso de los Tiempos Modernos hacia la consideración y atención dirigida ha-

34. I. Dubert García, op. cit., p. 39.

35. El presente trabajo ha sido elaborado a partir de la documentación notarial proporcionada por los núcleos rurales de Acebo, Aliseda, Brozas, Hoyos, Montánchez, Robledillo de Gata y Zarza de Montánchez, localizados en la mitad occidental de la actual provincia de Cáceres.

36. La evolución precisa de las proporciones del conjunto de testamentos interesados en lá designación de tutores, sobre el global de la muestra recogida es la siguiente:

1550-1599:31\% (9 testamentos del total de 29) 1600-1649: 16,7\% (6 testamentos del total de 36) $1650-1699: 45 \%(36 \quad \ll \quad \ll$ de 80$) 1700-1749: 30,0 \%(15 \ll \ll$ de 30$)$ $1750-1799: 81,9 \%(68 \quad \ll \quad \ll \quad$ de 83$)$.

37. F. J. Lorenzo Pinar, op. cit., p. 174. M. García Fernández, op. cit., p. 297.

38. Ph. Ariés, El niño y la vida familiar en el Antiguo Régimen, Madrid, 1987. Edición original francesa, 1960. Ll. Demause, Historia de la infancia, Madrid, 1982. Edición original inglesa, 1974. B. Jolibert, L'enfance au XVIIè siècle, París, 1981. B. Delgado, Historia de la infancia, Barcelona, 1998.

39. M. García Fernández, op. cit., p. 297. 
cia la infancia, en la que coinciden todos los trabajos al respecto ${ }^{38}$, unido a las transformaciones en el marco de las relaciones comunitarias, tendentes a un debilitamiento de su intensidad, así como a la necesidad de instrumentos de protección dotados de mayores garantías ${ }^{39}$ pueden sugerir las vías de interpretación del aumento global de las proporciones y de su particular intensificación en las décadas finales de estudio.

Conforme a lo observado en investigaciones previas, el recurso a la tutela testamentaria parece ser una práctica especialmente vinculada al grupo de varones adultos, a juzgar por los resultados ofrecidos tanto por los porcentajes considerados en su conjunto, situados en todo momento por encima del $80 \%$, como en términos relativos al volumen de escrituras de los respectivos sexos; pese a lo dicho, la mujer protagoniza una reveladora participación plenamente confirmada en la última centuria. No obstante la validez de las primeras apreciaciones globales, la justa ponderación del grado de interés suscitado por esta materia en ambos sexos precisa de una valoración de los resultados en relación al número de escrituras efectuadas por cada uno de ellos; de este modo, es posible ratificar la considerable inquietud que se refleja en las últimas voluntades expresadas desde el Quinientos por los varones, ligeramente atenuada en la siguiente centuria y convertida en referencia casi constante en los documentos registrados en el XVIII, en los cuales tales disposiciones se hallan presentes en más de las tres cuartas partes de las escrituras. Sin obviar la importancia de la evolución señalada a propósito de los varones, la actuación de la mujer resulta aún más interesante al comprobar en ella una iniciativa más dinámica que eleva las proporciones de tutelas ordenadas, desde el valor 0 del siglo XVI a poco más del $50 \%$ estimado para el Setecientos $^{40}$.

La comprensión de este comportamiento diferencial ha de efectuarse a la luz del trato discriminatorio hacia la mujer que perpetúa la normativa jurídica en esta materia. Si bien la desaparición de la madre no perturba en absoluto el normal ejercicio de la patria potestad, que por Derecho corresponde al varón, y ni siquiera las segundas nupcias del mismo lo inhabilitan en su función legítima como tutor y administrador de los bienes de sus hijos menores", la actuación tutelar de la mujer sin embargo sólo es posible en caso de no ser contrariada por manda testamentaria del cónyuge, quedando extinguida de forma automática en el momento en que la madre contrae nuevo matrimonio; de donde el interés por ratificar su nombramiento. Las causas justificativas de esta neta desigualdad en el reconocimiento de los derechos que asisten a uno y

40. La proporción de tutelas testamentarias dispuestas en relación al total de testamentos pertenecientes a uno y otro género evoluciona del siguiente modo:

Siglo XVI. Varones: $42,9 \%$ (9 interesados sobre él total de 21 escrituras).

Mujeres: $0 \%$ ( 0 interesadas sobre el total de 8 escrituras).

Siglo XVII. Varones: $40,9 \%$ (38 interesados sobre el total de 93 escrituras).

Mujeres: $17,4 \%$ (4 interesadas sobre el total de 23 escrituras).

Siglo XVIII. Varones: $77,4 \%$ (72 interesados sobre el total de 93 escrituras).

Mujeres: $55 \%$ ( 11 interesadas sobre el total de 20 escrituras).

41. A. Rodríguez Sánchez, «El poder familiar: la patria potestad en el Antiguo Régimen», Chronica Nova, 18, 1990, pp. 365-380. 
otro cónyuge ante el desempeño de la actividad tutelar se fundamentan en la mayor confianza mostrada hacia el varón, al que se presupone por definición un ánimo más constante y estable al que se entiende en el caso de la mujer por razón de su propia naturaleza, y de forma singular en la madre nuevamente casada ${ }^{42}$. Significativamente, dichas reservas están lejos de ser privativas del Derecho castellano moderno; antes bien, la voluntad de reforzar las garantías tutelares siendo el cargo detentado por una mujer resulta una constante apreciable en muy distintas cronologías y ámbitos geográficos ${ }^{43}$. A tenor, pues, de tales disposiciones y de los resultados ofrecidos por el análisis, en atención a la distribución por sexos y estado civil de los testadores, es posible la comprensión de las diferentes necesidades que condiciona el recurso a la tutela en cada uno de los casos.

Tabla 1. Estado civil de los testadores que disponen tutelas testamentarias: 1556-1799

\begin{tabular}{lccrrrr} 
& \multicolumn{2}{c}{ XVI } & \multicolumn{2}{c}{ XVII } & \multicolumn{2}{c}{ XVIII } \\
& Total & $0 \%$ & Total & $0 \%$ & Total & $0 \%$ \\
Varón casado & 8 & 88,9 & 31 & 81,6 & 65 & 90,3 \\
Varón viudo & 0 & 0 & 5 & 13,1 & 6 & 8,3 \\
N.C. estado varón & 1 & 11,1 & 2 & 5,3 & 1 & 1,4 \\
Total & 9 & 100 & 38 & 100 & 72 & 100 \\
Mujer casada & 0 & 0 & 1 & 25 & 3 & 27,3 \\
Mujer viuda & 0 & 0 & 3 & 75 & 8 & 72,7 \\
N.C. estado mujer & 0 & 0 & 0 & 0 & 0 & 0 \\
Total & 0 & 0 & 4 & 100 & 11 & 100
\end{tabular}

Aun cuando, de acuerdo a lo advertido, el interés por procurar la mayor cobertura hacia los menores describe una línea ascendente en las disposiciones testamentarias de ambos progenitores, el mayor porcentaje en términos absolutos y relativos de las vinculadas a varones debe ser interpretado como el resultado del ejercicio puntual de sus obligaciones, como titular de la patria potestad de sus menores ${ }^{44}$, y la conveniencia de expresar la voluntad en tal materia, al objeto de confirmar la tutela legítima de la madre u orientar las solidaridades a favor de los huérfanos. Por su parte, el aparente desinterés de la mujer obedece a la falta de necesidad de proceder en este sentido, dadas las garantías ofrecidas por la normativa legal al prolongar de manera automáti-

42. J. Febrero, op. cit., pp. 144-147.

43. El Derecho catalán bajomedieval impone en el ejercicio de la madre como tutora testamentaria o legítima una serie de condiciones, no requeridas en el caso de ser un varón el responsable del cargo, en tanto en la Italia de los siglos XIII al XV es práctica común el ejercicio de la tutela por parte de la madre si bien bajo vigilancia, supervisión y colaboración de los varones de la línea agnaticia del menor. Al respecto, véanse los trabajos ya citados de C. Forns de Rivera y N. Guglielmi.

44. E. Gacto, op. cit., pp. 42-44. 
ca la custodia de las personas y el patrimonio de los hijos menores en el cónyuge varón superviviente. Siendo así, tan sólo en circunstancias de total desprotección provocada por la muerte de ambos progenitores, haciéndose precisa la designación de tutores, se consiente, justifica y explica la aparición de instrucciones al respecto, recogidas indefectiblemente en las últimas voluntades de mujeres viudas y casadas en segundas nupcias, semejantes a las expresadas por Isabel Jiménez en cuyo testamento dispone:

«Nonbro por tutora y curadora de mis hixos a María Gómez, mi madre, la qual quiero lo sea y que no se le pida fianza porque desde luego yo la fío con mi persona y bienes (...). Y mando a mis hixos s'están muy obedientes a la dicha mi madre y no lo haziendo les desheredo en todo aquello que por derecho les puedo desheredar» ${ }^{45}$.

\section{Tabla 2. Relación familiar con el menor de los tutores designados por manda testamentaria: 1556-1799}

\begin{tabular}{lcccccc} 
& \multicolumn{2}{c}{ XVI } & \multicolumn{2}{c}{ XVII } & \multicolumn{2}{c}{ XVIII } \\
& Total & $0 \%$ & Total & $0 \%$ & Total & $0 \%$ \\
Madre & 7 & 77,8 & 29 & 69 & 59 & 64,1 \\
Tío/a & 0 & 0 & 7 & 16,6 & 9 & 9,8 \\
Abuelo/a & 0 & 0 & 2 & 4,8 & 4 & 4,3 \\
Hermano/a & 0 & 0 & 0 & 0 & 6 & 6,5 \\
Cuñado & 0 & 0 & 1 & 2,4 & 3 & 3,3 \\
Primo & 1 & 11,1 & 1 & 2,4 & 1 & 1,1 \\
Otros & 0 & 0 & 0 & 0 & 3 & 3,3 \\
No identificado & 1 & 11,1 & 2 & 4,8 & 7 & 7,6 \\
Total & 9 & 100 & 42 & 100 & 92 & 100
\end{tabular}

Por lo que respecta a la caracterización por sexo de los tutores nombrados, el protagonismo adquirido por la mujer se singulariza como el rasgo más notable y constante a lo largo de los tres siglos de análisis, aunque en paulatina disminución en consonancia con la mayor participación de distintos miembros del grupo familiar de sexo masculino, debido al creciente peso de las elecciones efectuadas por las madres testadoras. No obstante, la presencia de la mujer ha de entenderse en todos los casos vinculada a las figuras de la madre o la abuela, únicos tutores femeninos legitimados para el desempeño del cargo, por cuanto ambas constituyen una excepción al principio fundamental de incapacidad de la mujer para ser tutor, justificada por la presunción de entender en ellas una eficaz gestión por efecto de los vínculos afectivos que les unen a los menores ${ }^{46}$. La observación de los resultados evidencia nítidamente la expresiva importancia de la primera, sobre la cual recaen más de dos tercios del total de

45. A.H.P.C. Sección Protocolos. Brozas. Año 1652. Caja 3.324; legajo 2.

46. J. Febrero, op. cit., p. 144. 
los nombramientos registrados, reiterando una práctica no muy distinta a la comprobada por otras investigaciones para diferentes momentos y espacios, salvo por las menores proporciones y el comportamiento más sostenido que ofrecen las localidades alto-extremeñas.

De tal modo, las voluntades expresadas por los ciudadanos catalanes de los siglos XIII y XIV, los progenitores varones de las ciudades de Valladolid y Zamora a lo largo de la Edad Moderna o los onubenses del XVIII son conformes en señalar mayoritariamente a la madre sobre la cual, en fechas tardías de la centuria del Setecientos, son establecidos el $84,4 \%$, el $84 \%$ y en torno al $57,5 \%$ de los nombramientos efectuados por manda testamentaria en las respectivas localidades enunciadas ${ }^{47}$. Junto a la designación de la madre, las preferencias se dirigen en segundo término hacia la persona de los tíos de los pupilos, quienes absorben el 16,6\% de las tutelas otorgadas en el siglo XVII y el $9,8 \%$ de las registradas en el siguiente; tras ellos, los ilustrativos aunque decrecientes porcentajes que registra el grupo de no identificados, en los cuales habrá que presumir vecinos o conocidos, revelan la considerable labor de protección que compete a los miembros de la comunidad en situaciones críticas, como resultado de las obligaciones contraídas en el seno de las redes de solidaridades vecinales y comunitarias ${ }^{48}$.

Pese a verificarse el mantenimiento y preponderancia en todo momento de los tres grupos apuntados, el análisis en la larga duración descubre transformaciones expresivas que apuntan, a grandes rasgos, hacia una más acusada distribución de los porcentajes, a la mayor diversidad de los individuos implicados en las obligaciones tutelares, además de a la aparente pérdida de importancia de la función de la madre. No obstante estas primeras impresiones extraídas de los porcentajes globales, el análisis de los resultados discriminados por razón del sexo del testador, unido a la consideración de la creciente participación de la mujer en la disposición de tutelas testamentarias, permite ofrecer una valoración en su justo término.

Los nombramientos expresados por los varones confirman, en sentido opuesto a lo avanzado, el mantenimiento del grado de consideración de la esposa en estos cometidos, del modo en que reflejan los valores, situados en torno al $77 \%$ del total de las designaciones efectuadas por aquéllos, y las reiteradas expresiones justificativas de su designación:

47. C. Forns de Rivera, op. cit., p. 54. M. García Fernández, op. cit., p. 296. F. J. Lorenzo Pinar, op. cit., p. 174. D. González Cruz, op. cit., p.p. 244 y 246.

48. «Los vínculos personales del Antiguo Régimen tenían un valor ambivalente y no sólo unidimensional. Por un lado eran vínculos de integración que aseguraban la supervivencia de los individuos. Sobre todo, en la medida en que se trata de una sociedad en la que lo público no estaba separado de lo privado y en la que las funciones de gobierno, de protección, de seguridad social, de gestión de recursos y otros servicios no estaban administrados o garantizados por un ente público cono el Estado o por otras formas de asociación, sino que dependían en gran medida, directamente, de la acción de personas particulares (...)». J. M. Imízcoz Beunza, «Comunidad, red social y élites. Un análisis de la vertebración social en el Antiguo Régimen» en J. M. Imízcoz Beunza (dir.), Élites, poder y red social. Las élites del País Vasco y Navarra en la Edad Moderna, Bilbao, 1996, p. 28. 
«Y por quanto es grande la confianza y satisfaczión que tengo en Petronila Hernández, mi muger, por la mucha esperienzia que en ella e bisto y esperimentado en el buen modo de disponer y cuidar y administrar los vienes que Dios nuestro señor se a servido nos dar, pues con su ayuda y buenas disposiciones de dicha mi muger emos junttado vastanttes vienes, los que con su industria y buena administrazión se nos mantienen, y teniendo como tengo confianza en su abilidad e injenio, desde luego la nombro por tutora y curadora de todos mis hijos menores a la dicha mi muger, para que cuide de sus personas y vienes, administrándolos con toda qüentta y razón para que bayan en aumentto y no bengan en diminuzión $(\ldots){ }^{49}$.

En tanto, la mayor implicación femenina justifica la búsqueda de los candidatos entre otros miembros del grupo familiar, originando la apreciable dispersión de los porcentajes que caracteriza particularmente al último siglo de estudio. Ahora bien, la observación de unos y otros resultados, esto es los porcentajes globales y los obtenidos en atención al sexo del testador, evidencian evoluciones interesantes en la orientación en la que se disponen las solidaridades dentro y fuera del marco familiar.

Tales cambios se concretan en la reducción de la presencia de colaterales y ascendientes, simultánea a la mayor participación de los hermanos del pupilo, ya sea en representación propia o por medio de los cuñados en el caso de las hermanas. De acuerdo con las estimaciones reflejadas en las tablas elaboradas al respecto, es posible la comprobación de la baja paulatina de las proporciones de tíos $-16,6 \%$ en el Seiscientos, reducido al $9,8 \%$ en la centuria siguiente-, abuelos $-4,8 \%$ en el siglo XVII y $4,3 \%$ en los cien años posteriores- o primos $-11,1 \%, 2,4 \%$ y $1,1 \%$ respectivamente en cada uno de los siglos de estudio-, al tiempo que las relacionadas con las madres apenas sufren variaciones y se incrementa notablemente el concurso de los miembros vinculados al núcleo conyugal -esto es, hermanos y cuñados- en el transcurso de los siglos XVII y XVIII. Todo lo cual sugiere un tímido proceso de retraimiento de las solidaridades en el seno de la familia entendida en sentido extenso en beneficio de la mayor confianza mostrada hacia los miembros de la unidad nuclear, análogo a la evolución advertida por diversos autores en otros marcos sociales y geográficos, y que ha sido interpretada como los primeros «indicios del nacimiento de la familia moderna», por cuanto los cambios apuntan a una progresiva concentración de los apoyos y las relaciones afectivas y asistenciales en el agregado conformado por padres e hijos ${ }^{50}$.

49. A.H.P.C. Sección Protocolos. Hoyos. Año 1760. Caja 731; legajo 13.

50. M. García Fernández, op. cit., p. 296. 
Tabla 3. Preferencia en la elección del tutor en relación al sexo del testador: 1556-1799

\begin{tabular}{llcccccc} 
& \multicolumn{2}{c}{ XVI } & \multicolumn{2}{c}{ XVII } & \multicolumn{2}{c}{ XVIII } \\
Padre: & Total & $0 \%$ & Total & $0 \%$ & Total & $0 \%$ \\
& Madre & 7 & 77,8 & 29 & 76,3 & 60 & 76,9 \\
& Tí/a & 0 & 0 & 4 & 10,6 & 5 & 6,4 \\
Abuelo/a & 0 & 0 & 1 & 2,6 & 2 & 2,6 \\
Hermano/a & 0 & 0 & 0 & 0 & 4 & 5,1 \\
Cuñado & 0 & 0 & 1 & 2,6 & 2 & 2,6 \\
Primo & 1 & 11,1 & 1 & 2,6 & 1 & 1,3 \\
Otros & 0 & 0 & 0 & 0 & 1 & 1,3 \\
No identificado & 1 & 11,1 & 2 & 5,3 & 3 & 3,8 \\
Total & 9 & 100 & 38 & 100 & 78 & 100 \\
Madre: $:$ Tí/a & 0 & 0 & 3 & 75 & 4 & 33,3 \\
Abuelo/a & 0 & 0 & 1 & 25 & 2 & 16,7 \\
Hermano/a & 0 & 0 & 0 & 0 & 2 & 16,7 \\
Cuñado & 0 & 0 & 0 & 0 & 1 & 8,3 \\
Primo & 0 & 0 & 0 & 0 & 0 & 0 \\
Otros & 0 & 0 & 0 & 0 & 1 & 8,3 \\
No identificado & 0 & 0 & 0 & 0 & 2 & 16,7 \\
Total & 0 & 0 & 4 & 100 & 12 & 100
\end{tabular}

En cualquier caso, el grupo de consanguíneos, con independencia del sentido e intensidad con la que se expresa la confianza en él depositada, se singulariza como el principal sostén y recurso de los integrantes del mismo en situaciones conflictivas requeridas de redobladas ayudas, siendo ésta una realidad que se aprecia confirmada en declaraciones como la que sigue, inserta en el testamento de Francisco Sevillano:

"Yten, digo y declaro y tengo por bueno que mis parientes no pongan curador a mis hijos menores, sino que que se esté y pase por la horden que sobre ello dieren Bartolomé de Çiudad, su tío, y Francisco Calbarro, su primo (...), [a los I quales ruego los tengan consigo y administren sus personas y bienes como bien visto les fuere (...) "st.

Pese a lo dicho, las solidaridades vecinales mantienen, aunque en grado variable, una importancia destacable vigente hasta el último siglo de estudio, en justa lógica con la naturaleza de los vínculos establecidos en comunidades rurales tradicionales en las que el sentimiento de colectivismo forma parte de la concepción natural de las relaciones sociales ${ }^{52}$.

51. A.H.P.C. Sección Protocolos. Robledillo de Gata. Año 1584. Caja 1.169; legajo 21.

52. J. Casey y B. Vincent atestiguan la presencia de niños huérfanos y abandonados acogidos en los hogares de vecinos, no necesariamente sobrados de recursos económicos, como expresión de un concepto de solidaridad que rebasa los límites del círculo familiar. En igual sentido, en la Galicia de Antiguo Régimen, en la que alrededor de 1/5 parte de los niños sufrían la pérdida de al menos uno de los pro- 
El examen de la segunda fuente propuesta hace factible, por medio de las escrituras derivadas del discernimiento de las tutelas legítimas y dativas, el intento de completar el conocimiento de la dirección en la que son ordenadas las responsabilidades, desde la interpretación efectuada por la propia comunidad, las condiciones de vida que se derivan de las diferentes elecciones, así como los individuos implicados en todo el proceso. Aun cuando el estudio de las 179 escrituras de discernimiento de tutelas localizadas permita la aproximación en términos generales a las cuestiones apuntadas, la mayor proporción de las registradas en los núcleos del norte de la provincia ${ }^{53}$ propicia un mejor acercamiento a los usos particulares de la zona de montaña, aunque limita el nivel informativo que pudiera obtenerse de las restantes poblaciones y el análisis diferencial entre una y otra área geográfica.

Los procedimientos revelados por la documentación ponen de manifiesto la existencia de instrumentos netamente diferentes entre ambos espacios, determinantes de la diversidad de individuos concernidos y ocupados de la protección de los menores huérfanos. De tal modo, las localidades norteñas examinadas -Acebo, Hoyos y Robledillo de Gata- confirman la convocatoria de asambleas o juntas de parientes, bien conocidas en el caso francés, integradas por un grupo variable de familiares cuyo número se sitúa entre los cuatro y cinco partícipes en las constituidas en Acebo y Hoyos, y oscila ampliamente entre las cinco y quince personas allegadas al menor en el caso de las congregadas en Robledillo de Gata. Dichas asambleas son, en los núcleos mencionados, las ocupadas de atender a la designación de tutores y curadores, además de decidir y consentir sobre las distintas actuaciones de aquéllos referidas a cuestiones judiciales, manutención del menor o administración de sus bienes ${ }^{54}$. Por su parte, el discernimiento realizado en las localidades del centro y sur del espacio de estudio -Brozas, Aliseda y Montánchez- aparece ejecutado por las autoridades civi-

genitores, se comprueba la existencia de relaciones «que, al margen de vinculos de parentesco, se tejian entre las diferentes familias con el propósito de buscar seguridad en un mundo que ofrecia a la continua terribles sobresaltos y en el que la desaparición de un padre o una madre con un rebaño de niños (...) era un acontecimiento dramático, y más cuando los usureros se arrojaban encima de muebles y raices». J. Casey y B. Vincent, «Casa y familia en la Granada del Antiguo Régimen» en J. Casey et al., La familia en la España mediterránea (siglos XV-XIX), Barcelona, 1987, p. 185. P. Saavedra, La vida cotidiana en la Galicia del Antiguo Régimen, Barcelona, 1994, p. 199.

53. Los 48 testimonios recogidos para fechas del siglo XVI corresponden exclusivamente a las localidades de Acebo, Hoyos y Robledillo de Gata, representando las escrituras pertenecientes a los mismos el $76,3 \%$ y el $81,6 \%$ del total de las halladas para los siglos XVII y XVIII respectivamente.

54. «En la villa de Robledillo de Valdárrago (...) ante Jil Merchán, alcalde hordinario d'esta villa, y ante mi Gaspar Níñez, escribano público d'ella, y testigos; en presencia de Francisco Chorrero, padre de menores d'esta villa, presentes Alonso Çibdad y Alonso Herrero y Juan García y Francisco Herrero, Pedro Cibdad, Pedro Martín viejo, Hernando Marinero, Francisco Núñez, todos dehudos y parientes del dicho menor, y el dicho Juan Herrero, curador del dicho menor, les hizo relaçión de la puja y postura que hizo el dicho Juan de Canpos de los bienes y hazienda del dicho menor. Y prometió Juan de Canpos diez, y nueve mill maravedís por dos años con que no a de alimentar el menor. $Y$ aviéndose tratado y conferido por los dichos dehudos y parientes del dicho menor, los susodichos acordaron que se resçiba la puja que haze el dicho Juan de Canpos y se tome la mejora que haz (...)». A.H.P.C. Sección Protocolos. Robledillo de Gata. Año 1588. Caja 1.847; legajo 2. 
les o judiciales -gobernadores del partido, alcaldes ordinarios, tenientes de gobernación, justicias mayores, corregidores- bien a petición de los interesados, procediéndose a la ratificación formal de las tutelas testamentarias o legítimas, o por iniciativa y designación propia dando cumplimiento a la normativa establecida en relación a la tutela dativa ${ }^{55}$.

Tabla 4. Relación familiar con el menor de los tutores discernidos en asambleas: 1557-1799

\section{Relación parental}

Madre

Tío/a

Abuelo/a

Hermano/a

Cuñado

Primo

Padrastro

Otros

No identificado

Total
$X V I$

$\begin{array}{cc}\text { Total } & 0 \% \\ 2 & 4,2 \\ 14 & 29,2 \\ 0 & 0 \\ 1 & 2,1 \\ 3 & 6,2 \\ 1 & 2,1 \\ 0 & 0 \\ 0 & 0 \\ 27 & 56,2 \\ 48 & 100\end{array}$

XVII Total $0 \%$

18,3

XVIII

Total $0 \%$

17

26,9

17

44,7

25

11,8

23,7

11

0

2,6

0

1,I

0

3,2

0

2,2

0

0

0

36,5

29

100

100

Si bien es posible la comprobación documental de las distintas vías empleadas en la elección de los tutores, sin embargo el análisis de la ordenación de las responsabilidades tutelares ha de restringirse necesariamente a la interpretación derivada de las asambleas de parientes, dada la notable importancia de estos testimonios sobre el conjunto de las escrituras recogidas; resultado de la mayor predisposición a la escrituración notarial que parecen manifestar las localidades norteñas, a ellas corresponden el 83,8\% del total de casos documentados en todo el período de análisis.

Por tanto, a tenor de las elecciones efectuadas mayoritariamente por los consanguíneos, mediante su participación en las asambleas convocadas con motivo de la muerte del padre o ambos progenitores, se comprueba una significativa coincidencia en los individuos preferidos con los que fueran señalados a propósito de la designación por vía testamentaria, aunque en orden de importancia diferente.

55. «En el lugar de la Aliseda (...), ante mi el presente escribano y testigos infraescriptos pareció presente Ysabel Bonilla, viuda d'esta vezindad, a quien doy fee conozco, y dixo: que por providencia dada por su señoría el señor Don Pedro Bernardo de Sancho Yerto, juez de Quartel y Provincia, y por ante su escribano Francisco Andrada y Rodríguez, se le ha declarado por tutora y curadora de las personas y bienes de su menores, hijos havidos en el matrimonio que tubo contrahido con Antonio Estévez, ya difunto. $Y$ ahora poniendo en efecto su aceptazión, obligazión y correspondiente fianza para la seguridad de ellos, y siendo cierta y sabedora de lo que en este caso la toca y pertenece, otorgaba y otorgó que acepta en toda forma el dicho cargo de tutora y curadora (...)». A.H.P.C. Sección Protocolos. Aliseda. Año 1793. Caja 3.847; legajo 10. 
La observación de la tabla precedente muestra de forma acusada el relevante papel atribuido a los miembros de la comunidad, por extensión a las solidaridades vecinales, conforme demuestran a lo largo de toda la secuencia cronológica, y en particular en el siglo XVI, las proporciones acumuladas en el grupo de individuos no relacionados familiarmente con el pupilo. A pesar de lo dicho, es notoria la paulatina reducción de la importancia de las mismas, habida cuenta de la baja que experimentan los porcentajes, oscilantes entre el 56,2\% del Quinientos y el $29 \%$ que arroja el último siglo. Un movimiento decreciente, parejo al descenso de las proporciones representadas por la figura del tío - sin perjuicio de seguir manteniendo su presencia en una de cada cuatro tutelas discernidas-, que obra en favor de la designación de la madre como responsable de la custodia de la persona y bienes de sus menores. Es precisamente este último, el rasgo más reseñable de las transformaciones advertidas en la larga duración así como el más sobresaliente en cuanto a su significado.

El reconocimiento progresivo pero firme del papel de la madre $-4,2 \%$ en el siglo XVI, $18,3 \%$ y $44,7 \%$ en los siguientes, respectivamente-, en sentido opuesto a la tendencia al decrecimiento que sufre la confianza manifestada hacia el resto de los miembros de la comunidad, parece insinuar una actitud por parte de los electores de mayor consideración a los lazos afectivos y de asistencia natural, existentes entre los menores y su progenitor superviviente, tanto como de valoración positiva del núcleo conyugal como espacio y ámbito óptimo de desarrollo de la infancia, frente a la ruptura o anomalía que representa la delegación del cuidado de los pupilos en terceros ajenos a tal grupo. De este modo puede ser interpretada la rápida consolidación de la mujer en las responsabilidades tutelares, desde la ausencia entre los nombramientos más frecuentes efectuados en el Quinientos al protagonismo adquirido a finales del período de estudio, momento en el que acumula poco menos de la mitad del total de los discernimientos, siendo en todo caso el principal colectivo ocupado en tales funciones. Este resultado final es conforme, por lo que concierne al reparto de tutelas entre los diferentes grupos comprometidos, con los ofrecidos por la ciudad de Santiago de Compostela en el siglo XVIII, a excepción de ligeras modificaciones referidas a la menor participación de allegados y conocidos, posiblemente explicable por el más intenso debilitamiento de las solidaridades vecinales en poblaciones de carácter urbano como la mencionada. No obstante, los porcentajes muestran una significativa similitud, correspondiendo a la madre el $54,4 \%$ del total de las tutelas escrituradas, en franco predominio sobre el $27,2 \%$ que absorben los parientes indirectos o el $18,3 \%$ representado por las personas extrañas a la familia ${ }^{56}$.

\section{CONCLUSIONES}

Según se ha tratado de poner de manifiesto en las líneas precedentes, la tutela adquiere en el contexto de los grupos sociales tradicionales un relevante y amplio significado, habida cuenta de la finalidad asistencial que le compete y de las múltiples repercusiones que a nivel social, familiar y personal se derivan de su ejercicio.

56. I. Dubert García, Los comportamientos de la familia urbana en la Galicia del Antiguo Régimen. El ejemplo de Santiago de Compostela en el siglo XVIII, Santiago de Compostela, 1987, p. 93. 
Con relación a esta última evidencia, se ha advertido que la tutela representa para los adultos designados para tal cometido una carga dotada de gravosas responsabilidades y sometida a un férreo ejercicio de físcalización judicial, vistas las medidas garantizadoras con las que se pretende salvaguardar la integridad personal y patrimonial del pupilo; ello la convierte en una actividad escasamente atractiva en favor de la cual se hará precisa la disposición de medios coactivos e incentivadores para su aceptación. En tanto, y por lo que importa al grupo de consanguíneos, la orfandad y el ejercicio tutelar al que esta situación obliga supone una circunstancia susceptible no sólo de delegar en terceros el control del patrimonio familiar, cedido al menor por herencia, sino de propiciar la ruina del mismo por efecto de una ineficaz cuando no deshonesta gestión por parte del tutor. A la vista de estas reservas y suspicacias cobra entonces sentido el papel de los familiares reunidos en asambleas de parientes, ocupadas en decidir sobre las cuestiones personales y materiales de sus allegados huérfanos, la creciente disposición de tutores por vía testamentaria nombrados por los progenitores interesados en mantener un control cada vez más absoluto y preciso sobre tal materia, la preponderante designación de los consanguíneos para estas responsabilidades y las ocasionales referencias a los esfuerzos acometidos por los parientes de los menores al objeto de recabar para sí la gestión tutelar, en detrimento de posibles injerencias extrañas. En último término, el cúmulo de los factores concurrentes señalados se ha visto fielmente traducido en las condiciones de vida y grado de estima proporcionados al pupilo, principal sujeto concernido, en virtud de la naturaleza del designado y de la política tutelar que ella condiciona.

A tenor, pues, de la suma de consideraciones expuestas, esto es, de las delicadas implicaciones y efectos a nivel personal, pero también patrimonial, que se vinculan a la actividad tutelar y de la consciencia de todo ello, ha de ser ponderada la comprobación del aumento de la inquietud de los progenitores por disponer bajo su dominio el nombramiento de tutores y curadores, designados mayoritariamente entre el grupo de allegados, si bien dentro de una dinámica tendente a restringir la elección a los miembros del núcleo familiar. En apoyo de esta evolución, que ha parecido sugerir el desarrollo de una mayor preocupación por el cuidado de los menores huérfanos y la atención a sus necesidades afectivas y educativas dentro de un ámbito familiar más cercano e íntimo, la conveniencia de dotarlos de instrumentos de protección más fiables y los incipientes cambios ocurridos a fines del Setecientos en el seno de la familia -relativos a la preponderancia y distintas atribuciones asignadas al núcleo constituido por padres e hijos-, obran así mismo los resultados ofrecidos por las escrituras de discernimiento de las tutelas. En ellas vuelve a plasmarse tal cambio de orientación en las designaciones, en idéntico sentido y con igual significado.

Es decir, al término del Antiguo Régimen los viejos intereses de preservación del capital familiar y de cuidado personal del menor, se conjugan con una mayor sensibilidad hacia las circunstancias de la infancia que habrá de desarrollarse en la orfandad, y con las transformaciones operadas en el marco del emergente modelo de la familia moderna, dotada ahora de nuevas competencias sentimentales y educativas, para proporcionar un clima de mayor bienestar y atención afectiva a los menores huérfanos. 